\title{
HUMANIZATION OF COMMUNICATION IN THE EDUCATION OF THE HUMANISTIC IDEAL OF SENIOR TEENAGERS
}

\section{Trybulkevych K. H.}

\section{INTRODUCTION}

The vital activity of democratic countries of the world is ensured by the functioning of civil society, the spiritual sphere of which presupposes the rule of law, pluralism in ideology, real freedom of speech, press, conscience, and high level of political, legal and moral culture. But the main feature of this society is people with their inherent humanistic morality. The morality of members of civil society is based on the recognition of man as the highest value, and his rights as a priority of society and the state.

For a real progressive transformation of social relations, the creation of a democratic state governed by the rule of law, it is necessary to fill the ideals of people with new meaning, to humanize their inner world, cultivating humanity, mercy, tolerance, and kindness. Without the awakening of such moral phenomena as patriotism, responsibility, selfesteem, and diligence, we can hardly count on improving the situation in our country. Humanistic morality is a regulator of human behavior, a guarantor of respect for all people and nations, and their cultural heritage. Freedom is based on it. Traditionally, the Ukrainian mentality is characterized by a valued attitude to the native land. The priority in interaction with the world is kindness, justice, responsibility, conscientiousness, and diligence. These values of an individual in the period of transition to the market relationships, which have not yet become civilized, perform the functions of harmonization of personal and public interests, and provide a peaceful resolution of social conflicts, positively distinguishing Ukraine from other post-socialist countries.

Unfortunately, despite the great importance of these phenomena in people's lives, they do not have a proper place in the value system of the younger generation. Today, crime, drug addiction, resentment, and a nihilistic attitude toward moral norms are growing in the student community.

There is extreme egocentrism, a low level of communication culture, unwillingness to take responsibility, insufficient patriotism, loss of life optimism, and any ideals. An important place in the actualization of humanistic values belongs to secondary school, in particular extracurricular 
activities, where senior teenagers gain experience of humane treatment of themselves, other people, learn to protect nature, raise the level of culture of democracy.

\section{Education of the human essence of senior teenagers' personality}

Scientific approaches to the education of a humane personality in modern conditions have been developed in the studies of Bekh, Bilousova, Boryshevskyi, Honcharenko, Dubrovskyi, Duranov, Zhyrska, Kononko, Kuzya, Malovanyi, Naidyonov, Rostovtseva, Stolyarenko, Tanyukhin, Chorna, Shingireyi, etc. The humanization of school life is a necessary prerequisite for building a democratic society, whose citizens defend their rights and freedoms in a civilized way, as well as show personal interest in the development of the state through understanding the connection of personal interests with public ones.

Such a person will live for moral self-improvement, personal well-being, and the good of others, without disturbing the peace and harmony in society. The education of humanistic traits is the key to the European integration of our state when Ukraine enters the world community as an equal partner.

The urgency of the problem of senior adolescents' education is important since this age is a favorable ground for understanding their mental qualities and traits, socio-moral self-esteem, self-education, self-expression, and selfaffirmation. The main features of adolescence are the assessment of the effectiveness of their activities, relationships with peers and adults; formation and development of self-awareness.

Characteristic of senior teenagers, the growing need for communication, and expression of emotions lead to the increased influence of friends on the personality of teenagers. As a rule, the greatest intensity of the relationship of students acquires in leisure time. That is why extracurricular activities provide the most favorable conditions for the education of the humanistic ideal of senior teens.

Given the logic of the study, the humanistic ideal of senior teenagers can be understood the image formed in the individual consciousness of their "better self", which serves as a motive for the transformative activities of the subject, based on internalization and realization of basic moral values; principles of values to oneself, other people, Motherland, humanity, nature; awareness of their rights and freedoms and the ability to protect them ${ }^{1}$. The humanistic worldview is the ideological basis.

\footnotetext{
${ }^{1}$ Doroshenko K. H. (2003) Vykhovannia humanistychnoho idealu starshykh pidlitkiv $\mathrm{u}$ pozaklasnii diialnosti [Upbringing the humanistic ideal of older teenagers in extracurricular activities]. (PhD Thesis), K., 235 p., p. 21. (in Ukrainian) 
Starting an experimental study of the effectiveness of the technology of educating the humanistic ideal of older adolescents, we relied on the researches of Bern, Bekh, Bogdanova, Mudryk, Semichenko, who state that communication is one of the leading factors influencing the education of moral values of students. They suggested that the humanization of communication between students will have a positive effect on increasing the level of values towards themselves and others. After all, communication is a necessary condition for the entry of the individual into society. It provides the appropriation of a certain system of values and priorities, the inheritance of patterns of behavior, transmission, and receipt of information, the implementation of speech interaction with other people.

The process of communication is a "complex interaction of people, in which the exchange of thoughts, feelings, experiences, behaviors, habits, as well as meet the needs of the individual in support, solidarity, compassion, friendship, belonging, etc." 2 And the more diverse and richer human communication with others is, the more successful the personality develops. However, this process will be effective only if the principles of humanization of communication are observed.

Humanization of communication is one of the main components of education of the humanistic ideal of senior teenagers, characterized by the establishment of subject-subject interaction between participants in the communication process, the development of students' culture of communication, the formation of students' self-esteem, shaping the experience of the value related to a person the display by senior teenagers of the best qualities.

The priority sign of humanization of communication is the culture of communication. It characterizes a set of moral norms and behaviors that are based on a deep understanding of the value of another person and ensure the optimal course of communication between people. The effectiveness of communication is determined by the equivalence of the exchange of thoughts, feelings, and experiences with a partner, which involves a mutual spiritual, moral, and psychological return.

In organizing the experimental work on the humanization of communication, we used the results of researches by Bandura, Benedict, Bronfenbrenner, Gesell, Erickson, Levin, Mead, Piaget, Selman, Freud, Hevighurst, and guided by an eclectic interdisciplinary approach (Rice, Bekh), which is based on a comprehensive study of adolescent personality,

${ }^{2}$ HoncharenkoS. (1997) Ukrainskyi pedahohichnyi slovnyk. [Ukrainian Pedagogical Dictionary]. K.: Lybid, 356 p., p. 317. (in Ukrainian) 
taking into account its physiological, psychological, cognitive characteristics and features of social, environmental and anthropological development.

The study of the age characteristics of senior teenagers led us to the conclusion that the natural environment for the education of the humanistic ideal in this period is a group of peers because friends give the teenager strength and help to define the boundaries of their "I". With the help of friends, young people acquire the necessary personal and social skills that help them to become part of the adult world. Searching for optimal activities, as well as the conditions under which the humanistic ideal is most effectively formed, we assumed that such a form is extracurricular activities. Extracurricular activities are an integral part of the educational process of the school, one of the areas of organization of extracurricular activities of senior teenagers to educate them in the humanistic ideal.

In extracurricular activities it is possible to combine the purpose of education with the needs and interests of students and provided them the development of the ability to interact with themselves and the world through communication. The deepest and most vivid expression of the feelings of a young person, which contributes to personal growth and connection with the world, occurs during training sessions. Training helps to overcome the internal problems of the individual and teaches to interact with himself and others at a more constructive and qualitatively higher level.

Based on these statements, we decided that the optimal form of extracurricular activities to humanize communication is psychological and pedagogical training. We formed training groups based on seventh and eighth grades, guided by the principles of voluntariness and encouragement. The objects of the study were secondary schools № 53, 56, 57 of the city of Mykolayiv and Khmelnytskyi gymnasium № 2, in which experimental and control classes were allocated.

\section{Experimental work}

The experimental work covered 620 students. Verification of the representativeness of the sample was carried out according to the Student's formula, thanks to which we were able to obtain the most reliable results ${ }^{3}$ :

$$
n=\frac{N t^{2} p \cdot g}{N_{\Delta}^{2}+t^{2} p \cdot g}
$$

${ }^{3}$ Volovik P. N. (1969)Teoriya veroyatnosteyi matematicheskayas tatistika v pedagogike. [Probability Theory and Mathematical Statistics in Pedagogy]. K.: Radyanska shkola, 221 p., p. 120. (in Russian) 
The number of pupils according to the formula is 413 . To develop the culture of communication of senior teenagers, as an important manifestation of the humanistic ideal, we organized training groups of mixed type. Their activity was based on the principles of functioning of T-groups (development of personality in the interpersonal space) and G-groups (self-actualization and self-regulation).

Work in training groups of mixed type (which we identified as experimental and covered the activities of 620 students) included the following aspects: the development of self-affirmation by overcoming insecurity, rigidity, and insincerity; developing the ability to listen and understand another person, provided that they are aware of its value; formation of skills of situational analysis in interpersonal interaction; formation of self-confidence in the process of developing communication skills and understanding of one's value.

In contrast to the experimental ones, the activities of the control groups (covering 610 people) did not involve the humanization of communication through training sessions, but included two thematic classes on the topics "Learning to listen" and "A polite interlocutor". The training sessions included work with students of the average and low level of humanistic ideal's formation. After all, as evidenced by the observational experiment, both categories of senior teenagers can be described as those who do not have sufficient knowledge of the basics of communication culture. This was evidenced by observations of students, and conversations with them.

At the initial stage of experimental work, only $9.03 \%$ (56 students) of the total number had a high level of communication culture formation. Thus, the vast majority needed help in mastering the culture of communication. Pupils with a high level of communication skills also needed to practice their skills in practice and develop a fuller awareness of values towards themselves and other people.

In the work of training groups we relied on the interdependence of rational, emotional, and activity components of personal development, building training so that teenagers could not only develop their knowledge of communication culture, but also "live" emotionally the moment of personal communication. This stimulated them to carry out personally significant charitable activities.

Classes in training groups involved the acquisition of knowledge about the basics of communication culture and the development of practical skills and abilities of effective communication, which can be transferred through the scheme (Fig. 1). According to the scheme, we have developed a plan for training sessions: Acquaintance. Adoption of group work rules (2 hours); People nearby ( 2 hours); Facial expressions. Eye contact (1 hour); Gestures. Poses (1 hour); We learn to listen. Results (2 hours). 


\begin{tabular}{|l|l|}
\hline \multicolumn{1}{|c|}{ Culture of communication } \\
\hline $\begin{array}{l}\text { Knowledge: } \\
\text { - facial expressions; } \\
\text { - gestures; }\end{array}$ & $\begin{array}{l}\text { Skills and abilities: } \\
\text { - empathetically respond to the emotional state } \\
\text { - pose the interlocutor; } \\
\text { - eye contact; } \\
\text { - speech etiquette; } \\
\text { - rules of active } \\
\text { listening. }\end{array} \quad \begin{array}{l}\text { awareness of its value; } \\
\text {-analyze situations of interpersonal interaction; } \\
\text { - enter into effective communication with } \\
\text { others, adhering to speech etiquette; } \\
\text { - to express their thoughts and feelings in } \\
\text { accordance with the speech situation. }\end{array}$ \\
\hline
\end{tabular}

The purpose of these training was to activate the need of each teenager to improve communication skills, to acquaint students with the basics of communication culture, and to develop skills and abilities to implement it. Each lesson was based on an algorithm that contained six blocks:

1. Introduction. The actualization of the need for communication.

2. Performing exercises and practical tasks.

3. The message of theoretical material.

4. Performing exercises and practical tasks.

5. Reflection.

6. Lesson results.

The task of the first block was to stimulate the activity of senior teenagers, update their experience, and setting students up for productive work. The second block involved the implementation of exercises and practical tasks aimed at consolidating the material learned in previous classes and to prepare for the perception of new material. The message of the theoretical material took place in the form of dialogical conversations, in which all the information was presented based on the experience of students through questions and answers.

To learn new material, we used a set of exercises and practical tasks that contained new information. After each exercise and task, both in the second block and in the fourth, a mini-reflection was performed. During it, teenagers shared their impressions and experiences that arose during and after the exercises; tracked changes in the emotional state; compared their feelings with previous experience; allocated tools that helped or hindered certain types of communicative activities. 
These conclusions were summarized during the final reflection of the lesson (fifth block); new perspectives of personal development stood out. The sixth block provided for the definition of goals for further activities and the provision of tasks for independent work.

As the work in the training groups showed, this structure of classes allowed to combine theoretical and practical components and contributed to the assimilation of new information along with the consolidation of already known knowledge. Besides, special attention was paid to the creation of a person-centered field in which students received optimal opportunities to acquire the necessary communication skills and express their inner needs.

The educator's personality played an extraordinary role in this process. Accepting, understanding, and recognizing young people, the educator humanized the environment of their lives, showing due attention to all areas of senior teenagers' communication to provide them with emotional comfort and balance. The atmosphere of trust created in the classroom was transferred to everyday life, which contributed to the self-disclosure of students and the humanization of their communication.

According to the theory of moral development of Kohlberg, the formation of moral guidelines senior teenagers should correspond to the I-III level, according to which students adhere to the principles of compliance with generally accepted norms and begin to develop moral principles.

However, the first training session with students showed that they have a very simplistic understanding of the rules of interaction between group members. Thus, among the basic rules of group interaction, they stood out as follows: "Raise your hand", "Do not shout", "Do not disturb the order". By posing a system of questions as one of the effective methods of activating creative forces and updating knowledge about interpersonal interaction, the following system of rules of group work was developed together with students:

1. Trust the group. Tell only the truth.

2. Each member of the group receives at least one good word.

3. Do not insult a friend. Criticize actions, behavior but not the person.

4. Address others by name.

5. Listen carefully and don't interrupt anyone.

6. Communicate with everyone in the group.

7. Speak specifically.

8. Do not substitute the subject of the conversation.

The rule of trust in the group was not always perceived unequivocally the pupils were afraid to reveal the world of their feelings and experiences. However, during the training, communication barriers were reduced and 
trust in-group members was increased. Thus, in the first lesson, during the exercise "Presentation" (according to Prutchenkov"), which aimed to develop communication skills, develop listening skills, empathy and values to other people, teenagers briefly described their friend (after pair work, highlighting the features that distinguish it from others and for which it can be valued).

Speaking about her friend Rita, Katya noted: "Rita is a good friend and when I ask her for, she will always keep a secret". During the discussion, Valya asked Katya: "Will Rita keep a secret only when you ask her for? She can't understand it by herself?" Katya answered: "Yes. She knows when to keep something in a secret". Having heard this, Rita began to defend herself verbally. Students remarked because only the speaker had the right to speak in this situation. Valya later said, "I didn't notice Rita doing that". In this situation, Valya asked what was bothering her, because not so long ago she was trying to make friends with Rita. And Rita could not accept criticism with dignity, did not trust others because she was afraid of losing her authority. However, during the training, in the fifth lesson, there was an increase in the level of trust in the group, there was a greater looseness in the expression of their feelings.

Here are some statements from the group members after the fifth session (eight classes in total): "It's not easy to communicate with someone who isn't your friend, but I feel it works for me"; "I think I have found a friend, now I can trust him"; "Working in a group has changed something, we have less resentment and kicks during lessons and breaks," "I have learned how to communicate like a gentleman. Girls like it".

Training methods (finding and working out optimal forms of interaction with one's "I" and the world around in the process of reflective analysis and practical actions), conversations (the advantage is that the educator is in direct contact with the students. It helped to create an atmosphere of trust in the classroom and master the culture of communication, assisted to understand experiences, conflicts, find their causes, restore the inner integrity of the "I" and the attitude to themselves as values; find new meanings of life; bring to the choice of ways to overcome existing complications, solve critical situations and equip them with the knowledge that will help to understand humanistic ideal); testing (contributed to constructive self-analysis and further self-improvement of humanistic traits).

${ }^{4}$ Prutchenkov A. S. (2001) Sotsialno-psihologicheskiytrening v shkole[Social and psychological training at school].Seriya "Prakticheskayapsihologiya". M.: EKSMO-Press, 2001, 640 p., p. 222-224. (in Russian) 
During the interviews, the students' attitude to the problem of communication culture was considered and theoretical information was provided, which was tested immediately. Thus, to master the culture of communication, senior teenagers became acquainted with the concepts of facial expressions, gestures, poses, and eye contact; studied the rules of active listening and behavior of a person in a crowded place.

A lot of material was perceived ambiguously, and therefore a constant companion of the theoretical part of the training session was a discussion. Thus, in the fourth lesson, devoted to the features of facial expressions and eye contact, students received information that provoked discussion. Here is a fragment of it.

The tutor: "Obviously, everyone will agree that the gaze plays an extraordinary role in communication. It reflects our attitude to the interlocutor. What percentage of the conversation do you think we look at the speaker?

Andriy: "Probably seventy percent".

Anna: "And I think sixty".

Oleg: "When a person is unpleasant, I do not want to look at him at all".

Stanislav: "However, you see her but she will not disappear".

Andriy: "Maybe it takes ten or twenty percent".

Oleg: "I will tell you, Andriy, that it will take five percent. However, this does not mean that I look at everyone that way. Twenty to sixty percent of my attention is on other people".

The tutor: "Psychologists believe that we look at the interlocutor from thirty to sixty percent of the time talking, but this information is common. Maybe some of us hold the gaze on the other person's face longer, and some less. The main thing is that both you and those who communicate with you, it will not cause discomfort.

After all, it is known that prolonged holding of the gaze on the face of the interlocutor irritates him, and the inseparable gaze of wide-open eyes is perceived as a manifestation of aggression and a threat to the communication partner. Such controversy stimulated the analysis of one's behavior and caused changes in the view of interpersonal communication.

Much attention was paid to the fact that the acquired knowledge is not a template or a model for action, but only an indicative scenario of communication, because each person is individual, and within a certain ethnic or social group acquires even more significant differences. And the students found these differences. Thus, when considering the peculiarities of eye contact and human gaze, it turned out that different participants interpret the gaze in completely different ways: from contempt to dishonesty, while most psychologists (Lozovskyi, Piz, Rogov, etc.) tend to give it the meaning of suspicion or doubt. 
Special attention was paid to the development of empathy. For this purpose, we helped senior teenagers to model the image of them who aim to help others, feel the joy and anxiety of another with their heart, their thoughts, and experiences. We strengthened the students' belief that they were good and capable of doing good deeds.

Complications in this aspect of the work were inadequately underestimated self-esteem of $34.03 \%$ - 211 students (according to the results of the first stage of the experiment). Thus, one of the students, Vyacheslav, - an anxious and insecure young man who likes to show off his strength, said at one of the first classes: "Why do you say that you hope that I will cope with this task because I am kind, attentive? You think I'm bad and stupid".

Much training took place before Vyacheslav "warmed up", believed in his good nature and looked at others differently, and empathy exercises played a leading role in this process. The development of empathic understanding was given a place in each practical lesson, but the greatest attention was paid to the lesson "People around".

Thus, the purpose of the exercise "What are we like" (according to the method of Soldatova, Shaigerova, Sharova) ${ }^{5}$ was to develop a sense of unity of the group, the formation of empathy and values towards others. During the exercise, one of the participants was invited from the circle based on real or imaginary similarity, for example: "Olga, please come out because we have the same hair color (or similar because we are inhabitants of the Earth, the same height, etc.)". The person summoned went out and invited any of the participants to leave the circle in the same way. The exercise lasted until the whole group was in the center of the circle. At first, it was difficult for the students to distinguish the external and internal signs of community with others. Some of them could spend more than a minute in the center of the circle, thinking about whom to call and on what basis of similarity. The main signs of commonality that stood out: the same hair color, jeans are the same color, and fun.

However, the implementation of this exercise made the participants closer, forced them to discover new features in others and to see that those around them can have something in common with them, and thus be close. This was the first step in building empathic understanding.

Exercise "Attention, there is a man!" also played a significant role in the formation of empathy (according to Khryashcheva ${ }^{6}$ ). This task made an

${ }^{5}$ Soldatova G. U., Shaygerova L. A., Sharova O. D. (2006) Zhit v mire s soboyidrugimi: Treningtolerantnostidlyapodrostkov. [Living at peace with yourself and others: Tolerance Training for Teens]. M.: Genezis, 112 p., p. 29. (in Russian)

${ }^{6}$ Psihogimnastika v treninge[Psycho-gymnastics in training]. Pod red. N. Yu. Hryaschevoy (2010) - SPb :“Rech”, InstitutTreninga, 256 p., p. 99-100. (in Russian) 
unforgettable impression on the students. The exercise was as follows: each teenager received a card with the name of one participant. It was necessary to read its contents so that no one could see it. After the word "Start!", everyone began to follow the person whose name was written on the card to see what gestures this student was making, what was happening to him. At the same time, the participant had to remain unnoticed during the observation and tried to notice who was watching him. In the end, everyone answered the question "Who was watching you?", and if the answer was correct, the watching observer called the gestures he saw while completing the task. During the exercise, the following tendency was observed: tracking gestures was not another problem, but it was difficult to notice who was watching another student. Only $1 / 5$ of the group could unmistakably determine who was watching them. Performing this exercise caused a more active manifestation of observation concerning others, the development of the ability to combine certain activities with the observation of what is happening with others, and thus stimulated the formation of attentive attitude to people.

The exercise "Notice of a change" served as a continuation of working out of the given skill. During the exercise, one person was called to test his observation. He looks closely at everyone present, trying to remember their location and posture. After that, the observer was taken out of the door, and some participants changed the place, and positions. When the observer returned, his task was to name the changes he noticed. The exercise was repeated 3-4 times with other observers. Analyzing the changes and feelings that observers felt during their fixation, the students noted that at first they found change easily, felt a little confused, but the ability to mentally reproduce the original picture of the group members helped them establish the maximum number of changes. Teenagers noted to be attentive to people and notice external changes, it is necessary to keep in mind the question: "What are the others feeling now? What are they thinking about?" Both a person's posture and facial expressions can help to understand the world of his feelings. The following training were devoted to deepening the knowledge of facial expressions, gestures, postures, and practicing the skills to recognize and apply them.

At the lesson "Facial expressions and eye contact" students had the opportunity to independently acquire knowledge about the peculiarities of human facial expressions by completing the task "Can you read the mood?". During the performance, the members of the group were asked to recognize nine models of human facial expressions (strong anger; hostility; shy joy; disappointment, sadness; indifference; joy; deep sadness; surprise; stormy joy), schematically depicted on paper, and next to the ordinal number to 
indicate the emotion corresponding to a particular person. It was difficult for teenagers to be concentrated on this task. They needed a long demonstration of models of human facial expressions. There were difficulties with distinguishing shades of emotions. It was not easy for everyone to "read" the emotions of surprise and indifference. The disappointment was not always distinguished, and shy joy was called insidiousness, but when analyzing the task, comparing their answer with the correct one, the students understood the models of human facial expressions. The immaturity of adolescents' ability to learn about another person's mood from facial expressions has highlighted the need to focus the practical work on developing empathic skills.

The "Feel and Listen" exercise was designed to develop empathy. To do this, each participant received a card with the name of one of the above emotions. Students had the following instructions for the card: "Nobody but you should know what is written on the card. In pairs, one of you will tell a short story, trying to use facial expressions to convey your emotion. The interlocutor's task is to listen carefully, using the necessary gestures, and to understand what emotion the other is experiencing. Then you change roles". During the exercise, students used a wide range of aids. Thus, Yuryi, conveying the emotion of stormy joy, used facial expressions (eyebrows raised high, a wide smile), gestures (head raised, arms outstretched), and means of intonation (voice cheerful and loud). His partner, Anatoliyi, was so absorbed in Yuri's story that he took the meaning of the story, which was only a means of conveying emotion, not the truth.

Students gained new opportunities to express emotions. They came to understand how to support another if he/she has negative experiences. It means to help a person to discharge emotion, and to create conditions in which the most complete expression of emotions reduces their intensity for a while, after which it is possible to eliminate the source of negative experiences and prevent their recurrence. This is a manifestation of humanism. Observing the manifestations of emotions of strong anger, frustration, sadness, and grief, and hostility, teenagers learned to listen to the person around, in what mood he/she would be, and to accept a person as he/she is. This exercise helped to develop feelings of compassion and empathy, which is a condition for the development of empathy.

Reflection contributed to the humanization of communication. In the process, the teenagers shared their impressions of the exercise as follows: "I felt sorry for Andryi, I realized that he was deeply saddened. In such moments it is better to have a friend who listens to him" (according to Anatoliyi's answer), "This exercise made me understand: sometimes even the fact that you were just listened to brings understanding" (from Yana's answer). So the students, listening to others, showed them their 
understanding, respect, and valued them, which contributed to the formation of value attitude towards their personality, (because "if I am capable of good deeds, I am good"). Also, the experiment showed that there is a direct relationship between values towards oneself and others: if a teenager deeply despises his/her personality, he/she will despise and hate others, but if he/she feels respect and trust, he/she will also trust others and respect them.

The formation of a culture of communication among senior teenagers included the inculcation of information about "open" behavior, which consisted of gestures, postures, gaze, and even the manner of wearing clothes. The development of "open" behavior skills and the development of communication skills was the goal of the "Call for Trust" exercise. During the exercise, the students were divided into pairs. One partner showed secrecy and unwillingness to communicate openly. The second task was to show with the help of posture, gestures, and facial expressions in conversation how to inspire confidence in the interlocutor, and "open" him to communicate. Then they changed roles.

This exercise, along with the development of communication skills, helped to distinguish signs of "open" and "closed" behavior, influenced the development of empathy. Students used a wide range of means by which it was possible to "open" the interlocutor, and how they caused confidence in themselves, were not always immediately on the list, but later replenished it. Thus, during the reflection, Tatiana singled out among the means that help to "open" another person for communication, such as a smile and hugs. When her friend, Oksana, called the orientation of the body to the interlocutor with his head tilted to the side, Tatiana agreed with her and said that these tools will be used in communication, because they "opened" her for communication, and it worked. Thus, the exchange of ideas during the reflective analysis was important for the formation of a culture of communication between students and the acquisition of new experiences.

The exercise "Cheer up the partner" (after Girnyk and Shpalerchuk) ${ }^{7}$ had a similar character, in which the participants were tasked in turn to remember something sad in pairs, and to get depressed. The task of the partner was to cheer up the other and to make him smile. It was forbidden to touch the partner. Performing this exercise caused pleasant emotions in the group. Many of the participants showed their hidden sadness during the performance. For example, Mykhailo told Oleg about misunderstandings with his mother, that bothered him; Elena shared her concern about the dog's

${ }^{7}$ Hirnyk A. M., Shpalerchuk I. N. (2001) Treninh komunikatyvnykh umin (metodychnimaterialy). [Communication skills training (teaching materials)]. Praktychna psykholohiia ta sotsialna robota, № 2, p. 11-16, p. 14. (in Ukrainian) 
disappearance. The partners listened to the problems of the partners and with the help of facial expressions, gestures, and words tried to calm down first, and then make the other laugh.

It worked out for almost everyone. The teenagers thanked each other during the discussion because the painful problems no longer seemed so hopeless. However, not everyone coped with the task. Igor failed to make his partner laugh. During the discussion, the group expressed their opinion to Igor: "You told funny stories and burst out laughing, but the person was feeling sad, and she needed your attention first, and maybe advice, and then, probably, jokes".

Igor thought deeply and did not even object. In the next exercise "Anecdote", he told a funny story, staring into the eyes of the interlocutor, monitoring his inner state and reaction to the story, and when telling jokes in a circle was one of those who most accurately conveyed the content of the story and sense of the speech. Thus, interaction with peers and adults helped Igor realize the need to value others and work on his personality to develop a culture of communication.

We attached great importance in the art of understanding the other to the development of active listening skills. To do this, students were informed about the peculiarities of human perception and determined the rules of active listening. Mastering the rules of active listening was an inner need for senior teenagers.

The exercises "Back to Back", "Call for Confidence", "Anecdote", "Understand Me", "Broken Phone" and "I Wish" stimulated the development of communication skills, listening skills, empathic understanding, attentiveness and value of others.

In the process of the experiment, we created various conditions for communication: so that the interlocutors, showing communication skills in different situations, could optimally use them in real life. Thus, when performing the exercise "Back to back", teenagers were not able to receive information from others through gestures and facial expressions. For 3-5 minutes, participants maintained a conversation sitting with their backs to each other. Most of them spent the first minute exchanging a couple of phrases and only then found a common topic for conversation, and communication started. After completing the exercise, the students made the following generalizations: "It was not like talking on the phone, because the interlocutor was nearby, so it was difficult to speak at once. But you can get used to communicating like that, if there is a need, for example, when you want to say something in class to a friend at another side of the classroom " (Oles), "It is interesting and unusual to speak in this way, but it teaches to communicate differently than usual" (Rita). Thus, the unusual situation of 
communication aroused the interest of teenagers and led to the development of their communication skills.

When conducting exercises to develop the ability to engage in effective communication, express their thoughts and feelings about the speech situation, we paid attention to mastering the skills of speech etiquette. After all, without understanding the need to address others politely, to use normative vocabulary in communication, the communicative act will not be humane.

The fact that most of the training was conducted playfully optimized the formation of a culture of communication between students. On the one hand, in students acquired practical skills and abilities of humane attitude to people, to their inner world, and on the other, they trained their communication skills.

In the experimental work, we preferred simulation games, the relevance of which was caused by the need to find methods of processing new human behavior patterns in unfamiliar conditions, because they involve modeling situations and practice the behavioral skills of the individual, and the rules of behavior in them. We also used these games to test the rules of active listening, as one of the components of the culture of communication, which took place in the process of developing empathy and communication skills.

The exercise "Understand me" developed to listen carefully to the problem of the partner, to try to understand its essence. Here is what the teenagers said after the exercise: "It's weird, but I was completely understood (Olga)", "Knowing the rules of communication are to interfere with speaking, but it's at first glance. You just think more about words and understand more about others. In my opinion, this is an important thing" (Zhanna).

This exercise helped to develop a deep understanding of the inner world of another person, empathic perception of people around. But the key to effective communication is not only the ability to see the inner state in words but also to be able to accurately perceive the content of the message and convey it to another interlocutor as needed.

The exercise "Broken phone" was created to develop this skill. Students were offered the following instruction: "We will play in turn. Now one of you will remain, and five will go out the door. We will call them one by one so that they can listen to the text from a friend and pass it on to another as accurately as possible. It is forbidden to prompt spectators. Their task is to register mistakes when telling the text and to indicate (after the exercise) who made them". During the exercise, the text was read to the first participant. Then the second participant was called and the first to retell the text to him. Then the second told it to the third, and so on until the end. After 
the last answer the original was read. The game could be repeated two or three times with other participants. For retelling, we selected texts that carried a humanistic load.

The first passage revealed the essence of a good man, the second - the need to preserve the beauty of nature, and the third called to become responsible creators of their lives and the lives of others, and the Motherland. The texts were taken from the works of Amonashvili and Sukhomlynskyi.

Using such texts for interpretation, we pursued not only the goal of developing communication skills and the ability to listen but also the formation of values towards the Motherland, nature, another person based of kindness, responsibility, diligence, and justice. By retelling these passages, the students not only acquired the skills of attentive listening, the adequate transmission of the information, but also internally perceived the content of the text. When discussing the exercise, they expressed the following thoughts: "Not all my moral values are developed at a high level, but I know what to do now" (Oleg), "Being good is not a weakness. Kindness supports others, both people and nature need it" (Anastasia). To make the results of the analysis more objective, we offered students additional sources of analysis of their character traits. One of them was testing "Pleasant interlocutor" by Prutchenkov".

Analysis of test results, self- and mutual assessment of communication culture allowed us to conclude that senior teenagers have different levels of communication skills: $74.03 \%$ (459 students of experimental groups) can be attributed to the middle level and $25.97 \%$ (161 students) - to high. During experimental work, approximately $40 \%$ (248 students) of the experimental groups rose from the middle level to high, when in the control classes this figure was only $14.83 \%$ (92 students).

To obtain the most representative data and clarify information about the humanization of communication, the core qualities of which are the values of self and other people, we used the author's exercise "I wish", during which each group member said "I wish ..." and "I wish all of us ..." During this training, it was possible to observe the change of attitude among participants of the teams and the growth of the ability to openly, fully express their own opinions. Students wished each other and themselves confidence, freedom, patience, attention. For example one of the students, Irina, wished humanity, kindness, which she believed can help in any life situation.

${ }^{8}$ Prutchenkov A. S. (2001) Sotsialno-psihologicheskiytrening v shkole[Social and psychological training at school].Seriya "Prakticheskayapsihologiya". M.: EKSMO-Press, 640 p., p. 322-325.(in Russian) 


\section{CONCLUSIONS}

In the process of generalizing the data of testing, self- and mutual evaluation, exercises and observations of students, three levels of the culture of communication and value attitude towards themselves and other people as interdependent factors of the humanistic ideal of older adolescents were revealed.

The first level, high, is characterized by completeness, thoroughness, and deep awareness of senior teenagers of knowledge about the basics of communication culture. These students have a persistent need to deepen them for self-improvement. Teenagers with a high level of communication culture accept themselves, value their qualities, and respect the thoughts and actions of people around them. Pupils emotionally respond to the experiences of others, able to put themselves in the place of the interlocutor. They can listen and speak effectively, adhering to the humanistic principles and requirements of speech etiquette, to express their thoughts and feelings following the situation of speech.

The second level, intermediate, is characterized as follows: senior teenagers' knowledge of the basics of communication culture is complete, but not deeply understood. Students do not have a constant need to acquire knowledge about the basic features of the culture of communication, and they acquire them in the process of self-study. They are not fully aware of the value of their personality and other people.

The manifestation of empathy for others is unstable. Students can react emotionally to the experiences of others, but do not always want and can put themselves in their place, fully understand people around them and support them. The ability to effectively listen and speak by the humanistic principles and requirements of speech etiquette, to express their thoughts and experiences in the context of the speech situation is partially formed.

The third level (low) can be described as following: students' knowledge of the basics of communication culture is superficial. Senior teenagers do not need to obtain information about the features of facial expressions, gestures, poses, and eye contact; mastering the rules of speech etiquette and active listening. They do not believe in their strength. Emotionally respond only to the experiences of loved ones, but can't always listen to them carefully and provide moral support. They communicate without the rules of speech etiquette. They do not know how to express their thoughts and feelings under the situation of speech with humanistic principles.

The work on the humanization of communication has shown the indicators shown in the table, where there are the following abbreviations: exp. gr. - experimental groups, count. gr. - control groups, h. l. - high level, m. 1. - middle level, 1. 1. - low level, v.a. - value attitude, c. c. - the culture of communication. 
The dynamics of the formation of values towards themselves and other people and the culture of communication

\begin{tabular}{|c|c|c|c|c|c|c|c|c|c|c|c|c|}
\hline \multirow{3}{*}{ 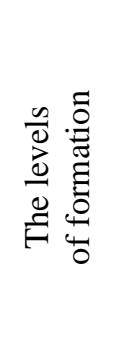 } & \multicolumn{6}{|c|}{$\begin{array}{l}\text { at the beginning of the } \\
\text { experimental work, } \%\end{array}$} & \multicolumn{6}{|c|}{$\begin{array}{l}\text { at the end of the } \\
\text { experimental work, } \%\end{array}$} \\
\hline & \multicolumn{3}{|c|}{ In exp. gr. } & \multicolumn{3}{|c|}{ In cont. gr. } & \multicolumn{3}{|c|}{ In exp. gr. } & \multicolumn{3}{|c|}{ In cont. gr. } \\
\hline & $\begin{array}{l}\frac{1}{0} \\
\infty \\
0 \\
\dot{0} \\
>\end{array}$ & 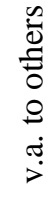 & ن & 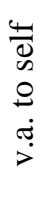 & 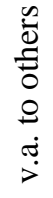 & ن & 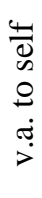 & 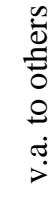 & $\begin{array}{l}\text { ن } \\
\text { ن }\end{array}$ & 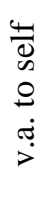 & 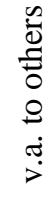 & $\begin{array}{l}ن \\
ن\end{array}$ \\
\hline 1. h. 1. & $\stackrel{+}{\infty}$ & $\hat{\infty}$ & $\begin{array}{l}\text { n. } \\
\text { a }\end{array}$ & $\bar{N}$ & n. & $\begin{array}{l}m \\
a\end{array}$ & $\hat{\tilde{a}}$ & $\hat{\tilde{a}}$ & $\hat{a}$ & $\begin{array}{l}\infty \\
\infty \\
\infty\end{array}$ & ๙ે & $\begin{array}{l}\infty \\
\infty \\
\infty\end{array}$ \\
\hline $2 \mathrm{~m} .1$ & $\stackrel{5}{0}$ & $\stackrel{q}{q}$ & ñ & 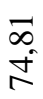 & $\frac{m}{\tilde{f}}$ & $\begin{array}{l}\text { N } \\
\text { nn }\end{array}$ & 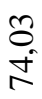 & 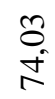 & 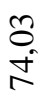 & $\stackrel{5}{\infty}$ & 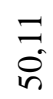 & $\frac{\infty}{6}$ \\
\hline 31.1. & $\frac{n}{6}$ & $\bar{n}$ & $\underset{\substack{N \\
\infty}}{\infty}$ & $\stackrel{\infty}{+}$ & $\begin{array}{l}\dot{+} \\
\infty \\
+ \\
+\end{array}$ & in & 0 & 0 & 0 & $n$ & $\hat{\hat{n}}$ & ๙ે \\
\hline $\begin{array}{l}\text { The } \\
\text { number } \\
\text { of } \\
\text { respon- } \\
\text { dents. }\end{array}$ & & 620 & & & 610 & & & 620 & & & 610 & \\
\hline
\end{tabular}

The information presented in the table shows that out of 620 students who participated in training on the formation of the basics of communication culture, values of self and others are formed at a high level in 155 students, and the rest of the participants, 465 senior teenagers are on the middle level.

Thus, as they learned the basics of communication culture as a mandatory component of humanizing communication and educating the humanistic ideal of senior teenagers, students began to realize the need for values to themselves and others, which confirmed our assumption at the beginning of the experiment. Based on the results of experimental research and analysis of psychological and pedagogical experience, we can conclude that one of the most important keys to the education of the humanistic ideal of senior teenagers is the humanization of their communication. 


\section{SUMMARY}

The research raises the problem of humanization of communication of senior teenagers to form in them a humanistic ideal, as developed in the individual consciousness image of his "best self", which serves as a motive for the transformational activity of the subject, based on internalization and realization of basic moral values; principles of values to oneself, other people, Motherland, humanity, nature; awareness of their rights and freedoms and the ability to protect them. Its ideological basis is a humanistic worldview.

Based on the experimental work, it was found that the humanization of communication of senior teenagers has a positive effect on the growth of their values towards themselves and other people under the conditions of involvement of senior teenagers voluntarily, desire to improve participation in psychological and pedagogical training; establishing subject-subject interaction between participants in the communication process; the creation by the educator of a personally oriented space to ensure the psychological comfort of students; cultivating the value of another person and forming the image of a "good other"; development of self-improvement in the process of overcoming rigidity and insecurity; developing the ability to listen and understand another person through awareness of his/her value; formation of skills of analysis of situations of interpersonal interaction; building self-confidence in the development of communication skills and understanding of self-value.

The humanization of communication of senior teenagers is also facilitated by mastering the basics of communication culture (disclosure of the concepts of facial expressions, gestures, poses, eye contact, speech etiquette, rules of active listening and behavior in a crowded place); the combination of rational, emotional and activity components in mastering the culture of communication: the use of methods of exercises, conversations, testing, supervision of students; appealing to the method of simulation games as a possible step in the readaptation of the personality of a teenager to build constructive behavior; encouraging students to carry out the process of self-education ensures the effectiveness of extracurricular activities to humanize the communication of them.

\section{REFERENCES}

1. Volovik P.N. (1969) Teoriya veroyatnostey I matematicheskaya statistika v pedagogike. [Probability Theory and Mathematical Statistics in Pedagogy]. K.: Radyanska shkola, 221 p. (in Russian)

2. Hirnyk A.M., Shpalerchuk I.N. (2001)Treninh komunikatyvnyk humin (metodychni materialy). [Communication skills training (teaching materials)]. Praktychna psykholohiia ta sotsialna robota, № 2, pp. 11-16. (in Ukrainian) 
3. Honcharenko S. (1997) Ukrainskyi pedahohichnyi slovnyk. [Ukrainian Pedagogical Dictionary]. K.: Lybid, 356 p. (in Ukrainian)

4. Doroshenko K. H. (2003) Vykhovannia humanistychnoho idealu starshykh pidlitkiv u pozaklasnii diialnosti [Upbringing the humanistic ideal of older teenagers in extracurricular activities]. (PhD Thesis), K., 235 p. (in Ukrainian)

5. Prutchenkov A. S. (2001) Sotsialno-psihologicheskiy trening v shkole [Social and psychological training at school]. Seriya "Prakticheskaya psihologiya". M.: EKSMO-Press, 640 p. (in Russian)

6. Psihogimnastika $\mathrm{v}$ treninge [Psycho-gymnastics in training]. Pod red. N.Yu. Hryaschevoy (2006). SPb:"Rech", InstitutTreninga, 256 p. (in Russian)

7. Soldatova G.U., Shaygerova L.A., Sharova O.D. (2010) Zhit v mire s soboy i drugimi: Trening tolerantnosti dlya podrostkov. [Living at peace with yourself and others: Tolerance Training for Teens]. M.: Genezis, 112 p. (in Russian)

\section{Information about the author:} Trybulkevych K. H., Doctor of Pedagogy, Head of the Department of Social and Humanitarian Disciplines, Admiral Makarov National University of Shipbuilding 9, Heroes of Ukraine Avenue, Mykolaiv, 54025, Ukraine ORCID ID: orcid.org/0000-0002-1907-7011 